\title{
Anti-CD19 Monoclonal Antibody
}

National Cancer Institute

\section{Source}

National Cancer Institute. Anti-CD19 Monoclonal Antibody. NCI Thesaurus. Code C112889.

Any monoclonal antibody directed against the cell surface glycoprotein CD19. 